\title{
Identification, Charecterization and Quantification of Process Related Impurities in Azimsulfuron Technical
}

\author{
M. PRABHU VENKATESH*, V. PARDHASARADHI, V. DHAYANITHI, \\ MANE AVINASH, S. PALIMKAR, R. KADAM SUBHASH \\ and HINDUPUR RAMA MOHAN
}

Advinus Therapeutics Ltd., 21 \& 22, Phase II, Peenya Industrial Area, Bengaluru-560058, Karnataka, India

venkatesh.prabhu@advinus.com

Received 8 September 2015 / Accepted 10 October 2015

\begin{abstract}
This manuscript describes identification, isolation and characterization of azimsulfuron impurities. Six impurities ranging from 0.05 to $0.15 \% \mathrm{w} / \mathrm{w}$ in azimsulfuron technical were detected by a simple reverse phase HPLC method. These impurities were isolated by prep-HPLC and were characterized using IR, ${ }^{1} \mathrm{H}$ NMR, ${ }^{13} \mathrm{C}$ NMR and LC-MS/MS. Based on the results obtained from different spectroscopic experiments, these impurities have been characterized as impurity A (2-amino4, 6-dimethoxy pyrimidine), impurity B (1-methyl-4-(2-methyl-2H-tetrazol-5-yl)- $1 H$-pyrazole-5sulfonamide) impurity $\mathrm{C}$ (phenol), impurity $\mathrm{D}$ ( $N$-[(4,6-dimethoxypyrimidin-2-yl)carbamoyl]-1methyl-4-(1-methyl-1H-tetrazol-5-yl)-1H-pyrazole-5-sulfonamide), impurity $\mathrm{E} \quad$ (1,3-bis(4,6dimethoxypyrimidin-2-yl)urea) and impurity F (phenyl (4,6-dimethoxypyrimidin-2-yl) carbamate).
\end{abstract}

Keywords: Azimsulfuron, Prep-HPLC, Impurities, Spectroscopy, Identification, Characterization

\section{Introduction}

Pesticides of new compounds are continuously synthesized and introduced in the market to cater the requirements of always greater selectivity towards a particular kind of crop and of always lower persistence in the environment ${ }^{1}$. Among new pesticides comprising with these properties are some sulfonylurea derivatives. Sulfonylurea herbicides are a group of pesticides widely used all over the world for controlling weeds in several crops, e.g., rice, wheat, maize, barley, sugar beet and tomato. Their rapid and good acceptance was due to the high efficacy at low application rates (10-50 g/ha) and very low acute and chronic mammalian toxicities ${ }^{2,3}$. The general structure of sulfonylurea is $\mathrm{R}_{1}-\mathrm{SO}_{2}-\mathrm{NH}-\mathrm{CO}-\mathrm{NH}-\mathrm{R}_{2}$, where $\mathrm{R}_{1}$ can either be an aliphatic, aromatic, or heterocyclic group connected by a sulfonylurea bridge to a $R_{2}$ group that can either be a triazine or a pyrimidine ring ${ }^{4}$. 
Sulfonylurea ${ }^{5}$ herbicides are well known as being highly beneficial for controlling undesirable vegetation in agronomically desirable crops including corn, cereals such as wheat and barley. They worked on a broad range of grasses and broadleaf weeds, but not on crops they are designed to protect crops like rice, wheat, barley, soybean, maize and many others are able to metabolize sulfonylureas safely. Sulfonyl urea derivatives containing pyrazole ring (pyrazole sulfonylureas) found to exhibit pronounced herbicidal activity; especially, those in which sulfonyl ureabridge is attached to $5^{\text {th }}$ position of pyrazole ring (pyrazole -5-sulfonyl urea derivatives) are found to be more selective for rice plants from paddy weeds.

One of this class of sulfonylurea herbicides, azimsulfuron or 1-(4,6-dimethoxypyrimidin2-yl)-3-[1-methyl-4(2-methyl-2H-tetrazol-5-yl)pyrazol-5-yl sulfonyl] urea, developed by DuPont is a low toxic, broad-specturm, highly selective sulfonylurea herbicide and has been found to be particularly useful as post emergent herbicide for weed control in rice-paddies and suppression of barnyard grass in rice. It is effective in controlling perennial weeds at very low application rates (6 - $25 \mathrm{~g}$ of active ingredient per hectare) where as higher concentrations are needed to control annual weeds ${ }^{6}$. The mechanism of action of azimsulfuron, that it affects sensitive weeds through inhibition of the enzyme acetolactate synthase (ALS), the key enzyme involved in branched-chain amino acid biosynthesis in plants and micro-organism. Inhibition of ALS leads to the cessation of cell division and subsequent growth processes in plants.

The process for preparation of azimsulfuron ${ }^{7-9}$ involves coupling of 1-methyl-4-(2methyl-2 $H$-tetrazol-5-yl)- $1 H$-pyrazole-5-sulfonamide with phenyl (4,6-dimethoxypyrimidin2-yl)carbamate in the presence of base as shown in (Figure 1).

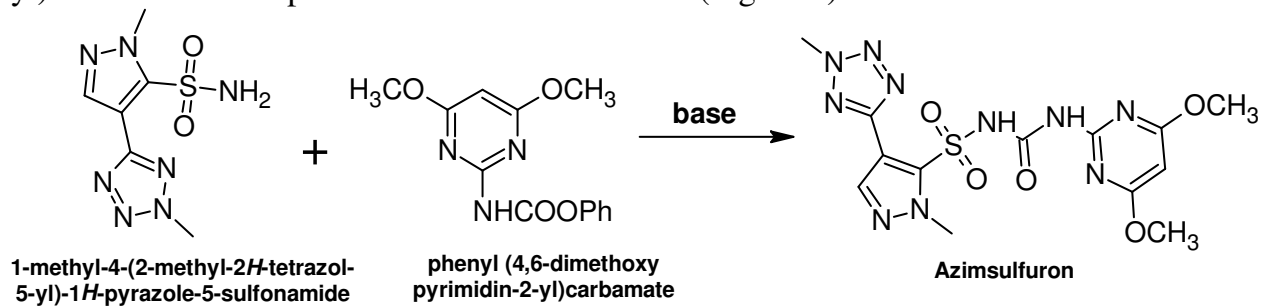

Figure 1. Preparation of azimsulfuron

To date only few reports are available on degradation study of azimsulfuron ${ }^{10-14}$ which indicating necessity of further exploration in this area. In addition to this, some kinetic data of azimsulfuron also have been reported without any indication of detected metabolites ${ }^{10}$. To the best of our knowledge, this is the first report on identification, isolation and characterization of azimsulfuron impurities. The main objective of the present work is to develop HPLC method for separation of azimsulfuron and its associated impurities; identification and characterization of these impurities; synthesis or isolation (from technical sample of azimsulfuron) of the impurity standards; and quantification of these impurities in the azimsulfuron technical.

\section{Experimental}

Azimsulfuron technical material (research sample) was supplied by Rallis India Ltd. HPLC grade acetonitrile was procured from Merck Co., Mumbai, India. A. R. grade potassium dihydrogen phosphate and G. R grade $88 \%$ orthophosphoric acid was procured from Merck Co. Mumbai, India. Milli-Q water was collected from Elix Millipore water purification system. 
HPLC grade dichloromethane was purchased from Spectrochem, Mumbai, India. A. R. grade phenol was purchased from Sigma-Aldrich, India. Inertsil C8 $(250 \times 4.6 \mathrm{~mm}, 5 \mu \mathrm{m})$ column was procured from GL-Sciences Inc. Japan. Phenol (Impurity-C) and 2-amino-4, 6dimethoxypyrimidine (Impurity-A) were procured form Sigma Aldrich, India. Impurities D and $\mathrm{E}$ were isolated by using preparative HPLC as discussed in below, whereas Impurity B and $\mathrm{F}$ which are also the key starting materials of azimsulfuron (Figure 1) were prepared by following reported synthetic protocols ${ }^{6-8}$.

\section{High performance liquid chromatography (Analytical)}

Initial screening of the technical material of azimsulfuron for its composition was performed using HPLC. Waters HPLC system equipped with Alliances 2695 series low pressure quaternary gradient pump along with photo diode array detector equipped with auto sampler has been used for the analysis of samples. The data was collected and processed using Waters "Empower 2" software. An Inertsil C8 $(250 \times 4.6 \mathrm{~mm}, 5 \mu \mathrm{m})$ column was employed for the separation of impurities from azimsulfuron. The mobile phase optimized for separation of the impurities from azimsulfuron active ingredient was a linear gradient from $10 \mathrm{mM}$ potassium di-hydrogen phosphate, $\mathrm{pH}$ adjusted to 3.0 with ortho phosphoric acid (component A) and acetonitrile (component B). The initial ratio was 70:30 (v/v):: A:B; the amount of B was then increased from 30 to $80 \%$ in $10 \mathrm{~min}$ and held for $5 \mathrm{~min}$ before being returned to the initial conditions in $5 \mathrm{~min}$. The column was equilibrated for $5 \mathrm{~min}$ before performing the next injection. Chromatography was performed at room temperature and the mobile phase flow rate was $1.0 \mathrm{~mL} \mathrm{~min}^{-1}$. The column eluent was monitored at $220 \mathrm{~nm}$. The injection volume was $10 \mu \mathrm{L}$. The sample concentration was approximately $0.4 \mathrm{mg} \mathrm{mL}^{-1}$.

\section{Mass spectrometry ( $L C-M S / M S)$}

Based on the obtained HPLC chromatogram of technical material, it was noticed that there were 6 impurities which are greater than $0.1 \%$ in active ingredient. In order to get mass spectral information of each of these impurities, LC-MS/MS was used. LC-MS/MS analysis has been performed on API 2000, mass spectrometer (Applied Biosystems). The analysis was performed in positive ionization mode with turbo ion spray interface. The parameters for ion source voltage IS $=5500 \mathrm{~V}$; declustering potential, DP $=70 \mathrm{~V}$; focusing potential, $\mathrm{FP}=400 \mathrm{~V}$; entrance potential, $\mathrm{EP}=10 \mathrm{~V}$ were set with nebulizer gas as air at a pressure of $40 \mathrm{psi}$ and curtain gas as nitrogen at a pressure of 25 psi. An Inertsil C8 (250*4.6 mm, 5 micron) column was used for the separation. The mobile phase was a mixture of $0.05 \%$ formic acid in water and acetonitrile. The same mobile phase was used for negative ionization mode with turbo ion spray interface. The analysis was performed at a flow rate of

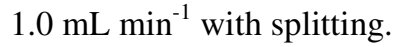

\section{High performance liquid chromatography (preparative)}

In addition to the mass spectral information of each of the impurities, it was required to have ${ }^{1} \mathrm{H}$ NMR and ${ }^{13} \mathrm{C}$ NMR of each impurity in order to confirm the structure of the impurities. For this purpose and also for the purpose of having standards of impurities for quantification, these impurities were isolated using prep HPLC.

An agilent prep-HPLC system equipped with 1200 series pump, photo diode array detector, auto sampler fitted with $5000 \mu \mathrm{L}$ loop and 1200 series preparative fraction collector was used. The data was collected and processed using Agilent "Chemstation" software. An inertsil C18 column $(250 \times 20 \mathrm{~mm}, 5$ micron $)$ was employed for loading the sample. An analytical method was developed in isocratic mode separately to resolve two 
impurities, followed by scaling up the same method for prep-HPLC to collect the required impurity fractions. The mobile phase consisted of $0.05 \%$ formic acid in water and acetonitrile in the ratio of 60:40 (v/v). The flow rate was set at $20 \mathrm{ml} \mathrm{min}^{-1}$. Detection was carried out at $220 \mathrm{~nm}$. Approximately $100 \mathrm{mg} \mathrm{mL}^{-1}$ of sample was prepared using acetonitrile and water in the ratio of $90: 10(\mathrm{v} / \mathrm{v})$ as diluent to load in to the column.

\section{NMR spectroscopy}

${ }^{1} \mathrm{H}$ NMR and ${ }^{13} \mathrm{C}$ NMR of each of the isolated impurities were recorded. The ${ }^{1} \mathrm{H}$ and ${ }^{13} \mathrm{C}$ NMR experiments were carried out at precessional frequencies of $399.939 \mathrm{MHz}$ and $100.574 \mathrm{MHz}$, respectively, in DMSO-d6 at $25{ }^{\circ} \mathrm{C}$ temperature on a Varian-400 FT NMR spectrometer. ${ }^{1} \mathrm{H}$ and ${ }^{13} \mathrm{C}$ chemical shifts are reported on the $\delta$ scale in ppm relative to tetra methyl silane (TMS).

\section{FTIR}

IR spectra of azimsulfuron and its impurities were recorded in the solid state as $\mathrm{KBr}$ dispersions, by using Perkin-Elmer Spectrum 100 series FTIR spectrophotometer with the diffuse reflectance sampler (DRS) technique.

\section{Results and Discussion}

\section{Detection of impurities by HPLC}

Typical analytical HPLC chromatogram of azimsulfuron spiked with its impurities obtained by using the HPLC method is depicted in Figure 2. The targeted impurities under study are marked as impurity A, B, C, D, E and F eluted at retention times of about 5.3, 5.7, 7.5, 8.4, 10.1 and $10.3 \mathrm{~min}$., respectively, while azimsulfuron eluted at about $9.6 \mathrm{~min}$.

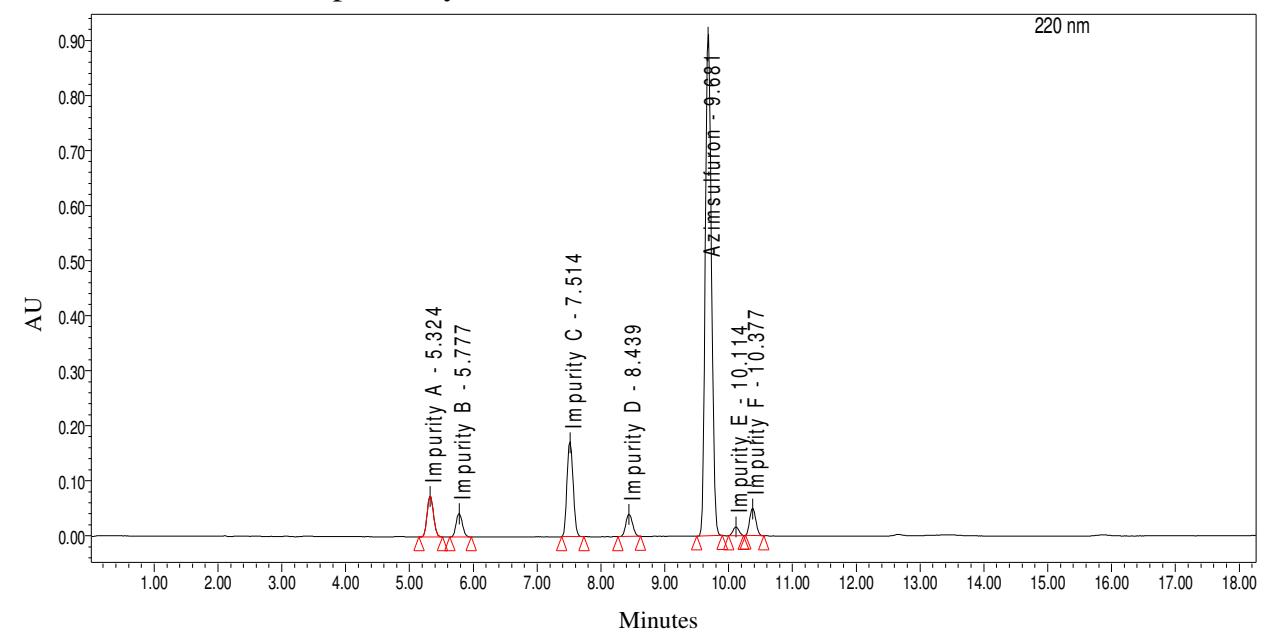

Figure 2. A typical HPLC chromatogram of azimsulfuron spiked with impurities

\section{Isolation of the impurities by prep-HPLC}

As discussed, a simple reverse phase chromatographic system was used for isolation of impurities. In this chromatographic system, azimsulfuron eluted at about 14 min whereas the impurity D eluted at about $13.1 \mathrm{~min}$ and impurity E eluted at about $14.9 \mathrm{~min}$. The impurity D fraction was collected between 13.0 and $13.4 \mathrm{~min}$, impurity E fraction was 
collected between 14.7 and $15.0 \mathrm{~min}$. The impurity fractions were concentrated by evaporating acetonitrile portion at room temperature under high vacuum on a Buchii Rotary evaporator Model R124. The concentrated aqueous layer containing individual impurities were extracted into methylene chloride. These fractions were concentrated by evaporating methylene chloride layer at room temperature under high vacuum to get the desired impurity. Purity of these impurities was tested in analytical mode and was found to be $97.1 \%$ and $96.3 \%$ (Figure 3), respectively, before carrying out spectroscopic experiments.
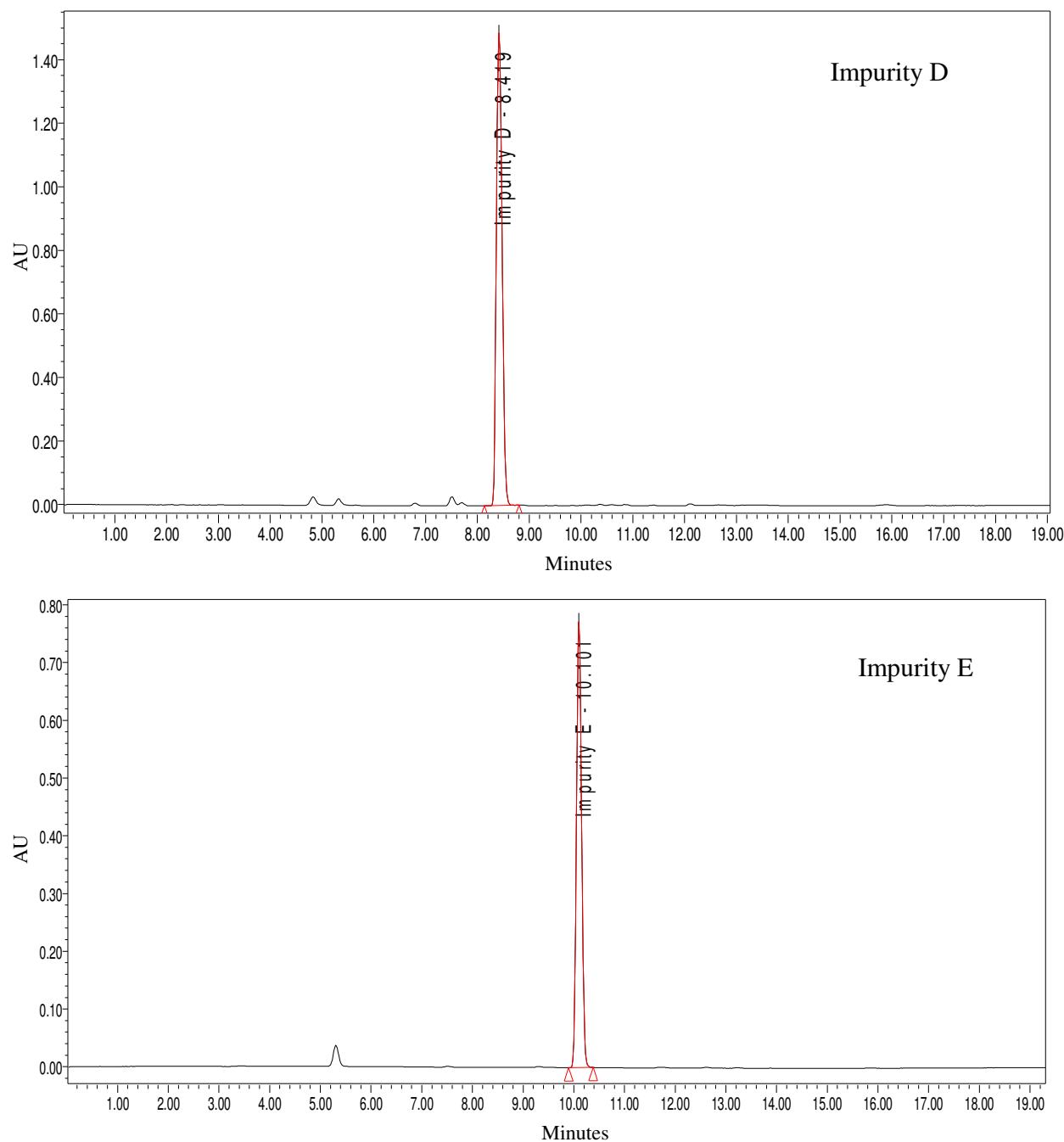

Figure 3. HPLC chromatograms of isolated impurities D and $\mathrm{E}$

\section{LC-MS/MS analysis}

LC-MS/MS analysis of azimsulfuron and impurities was performed using the chromatographic system as described. Results of LC-MS/MS analysis revealed that azimsulfuron, impurity-A, B, C, D, E and F (Figure 5) exhibited molecular ion at $m / z 425.2(\mathrm{M}+1), 155.9(\mathrm{M}+1)$, 
$244.3(\mathrm{M}+1), 93.1(\mathrm{M}-1), 424.8(\mathrm{M}+1), 337.1(\mathrm{M}+1)$ and $276.0(\mathrm{M}+1)$ amu (Figure 4), respectively and fragmentation pattern (Table 1). Based on the impurity-D fragmentation pattern it was decided that the impurity was similar to that of azimsulfuron which might be a positional isomer (Figure 6-9).
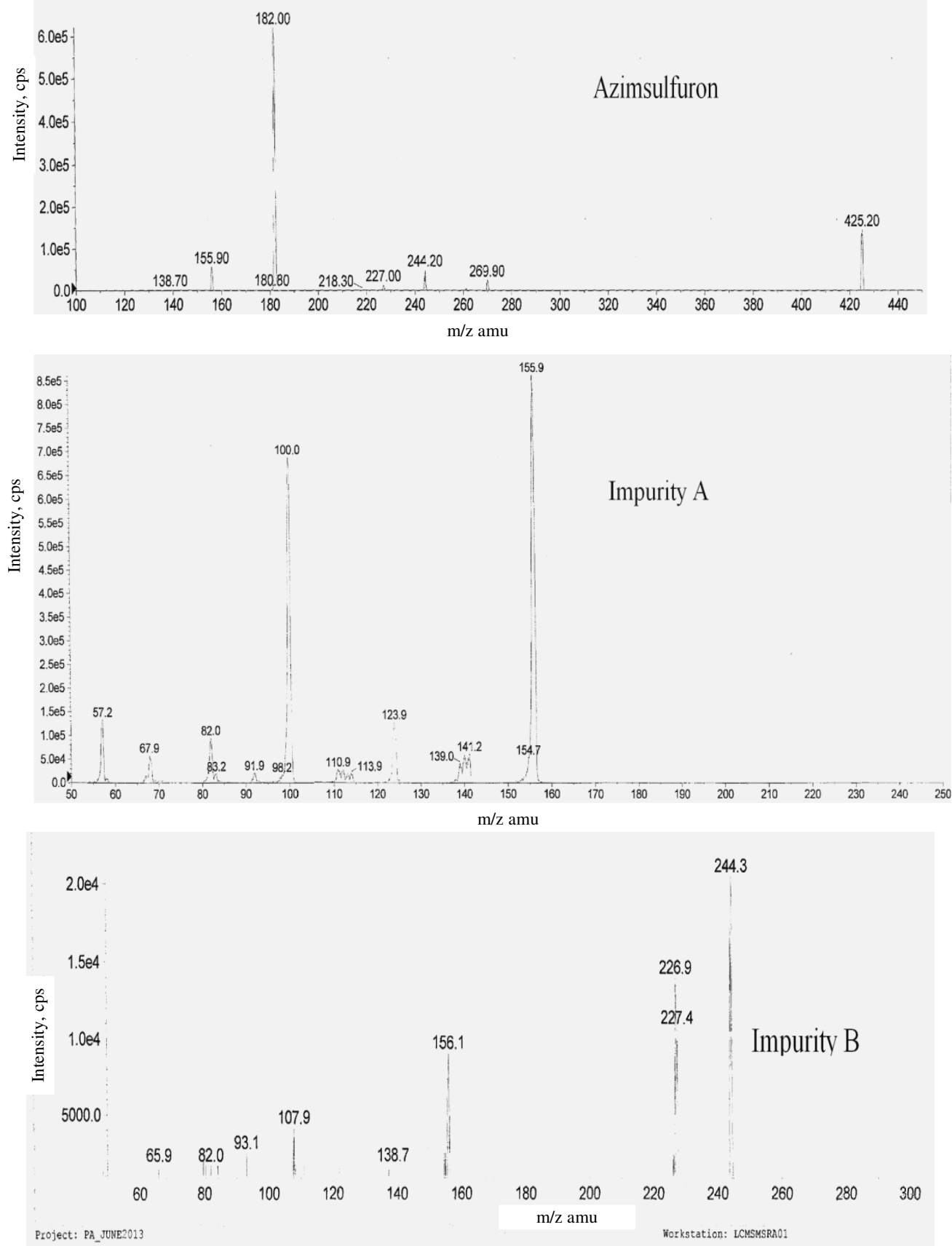

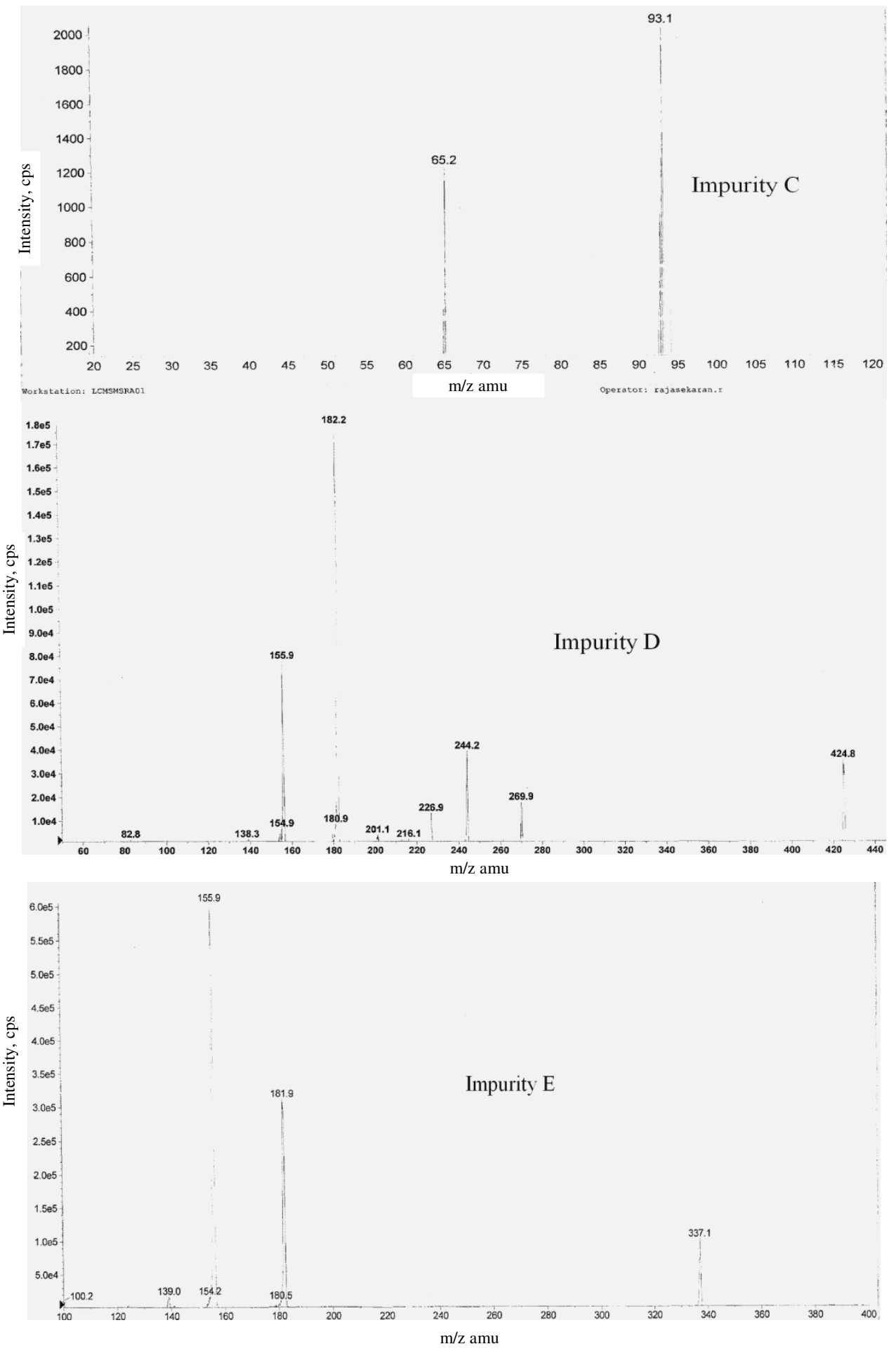


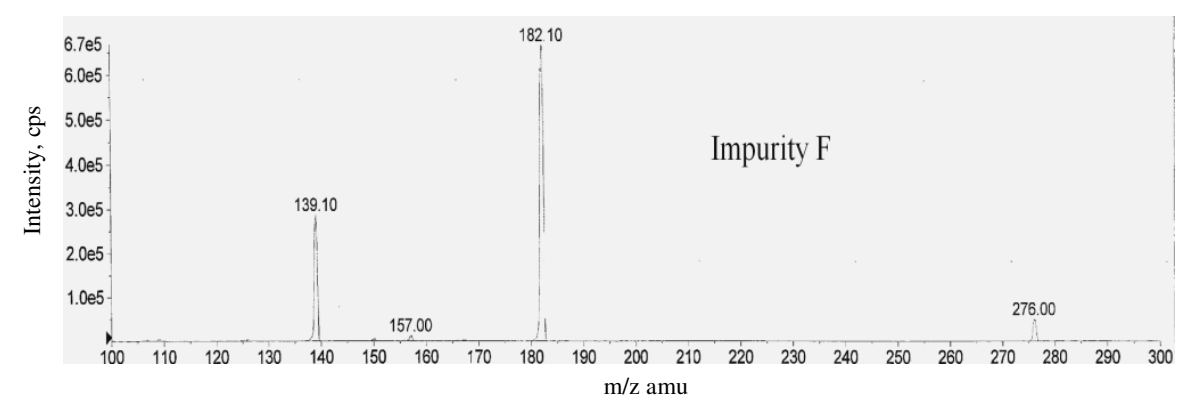

Figure 4. LC-MS/MS spectrum of azimsulfuron and impurities

Table 1. Mass spectral data of major fragments for the azimsulfuron and its impurities

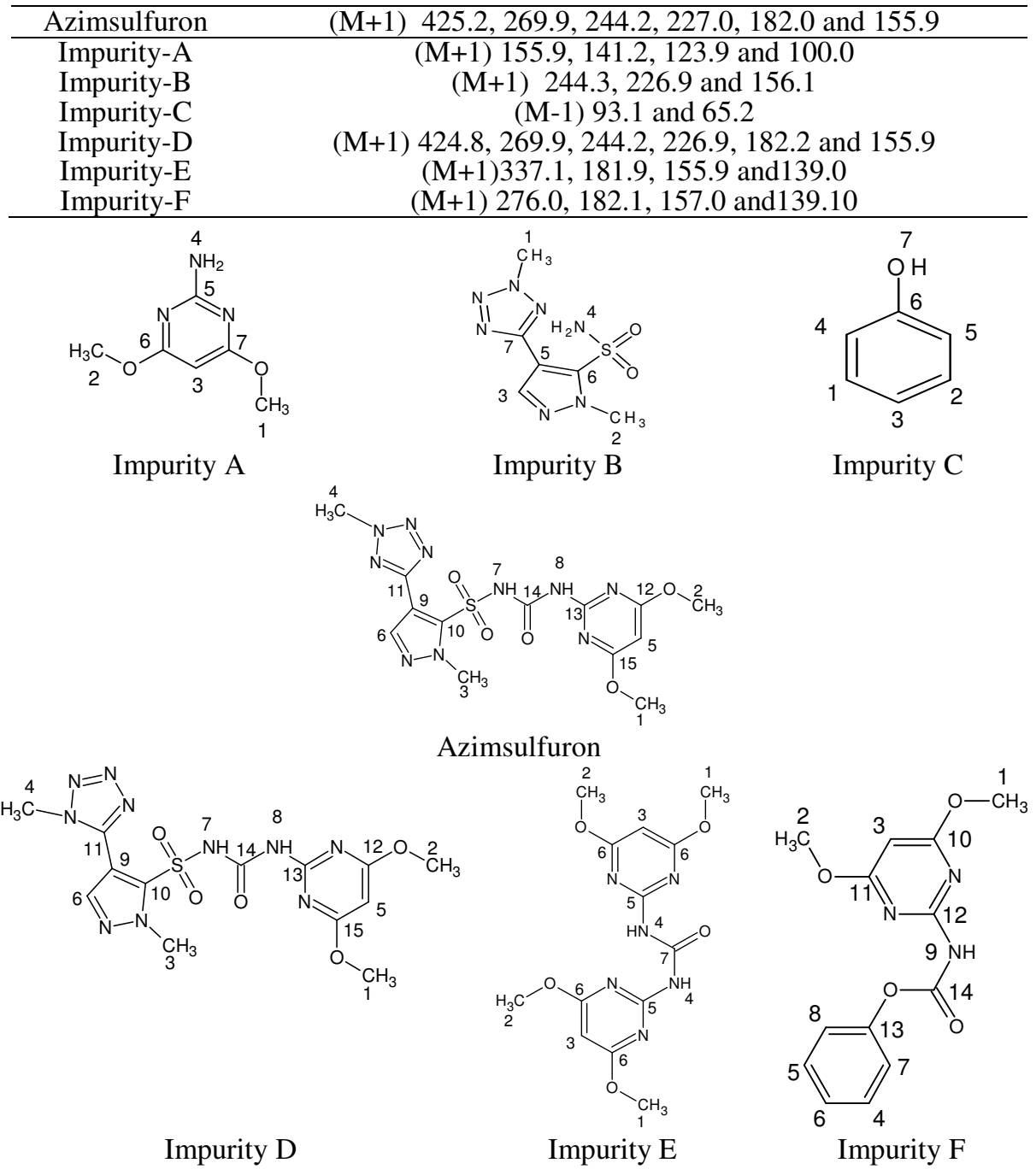

Figure 5. Chemical structures of azimsulfuron and its impurities 


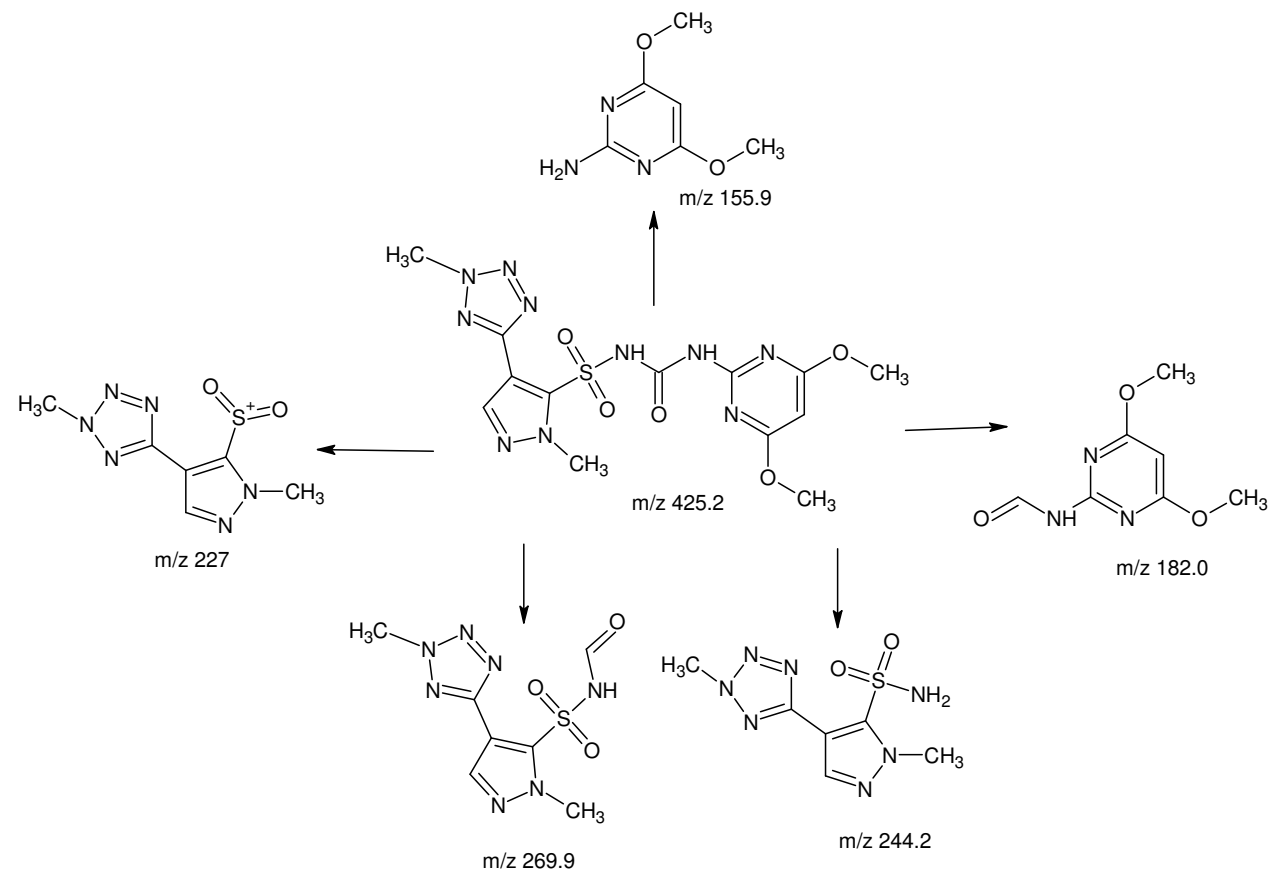

Figure 6. Proposed fragmentation pathways of azimsulfuron

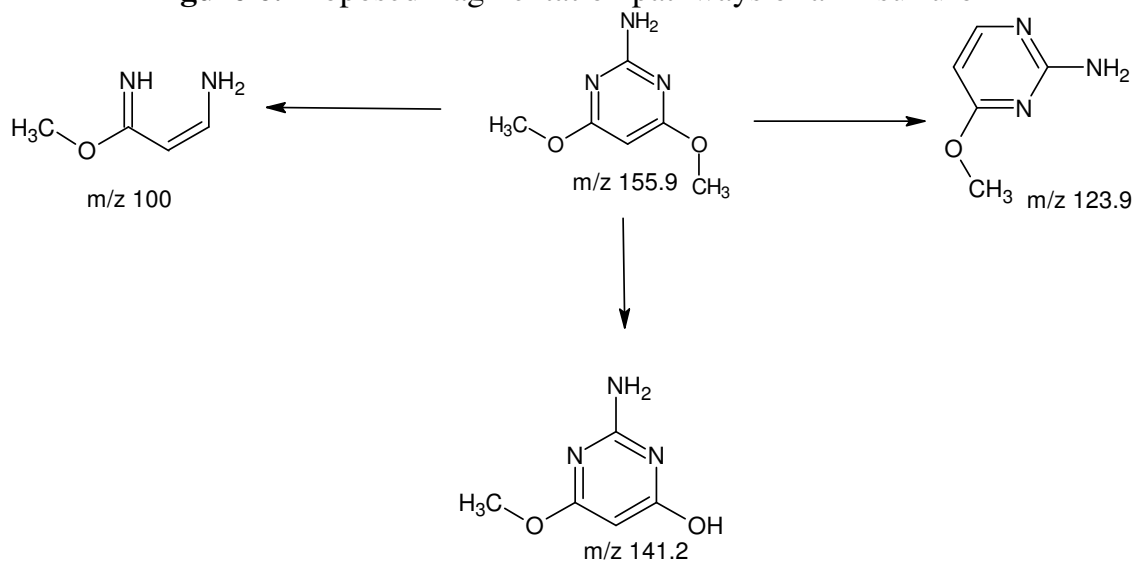

Figure 7. Proposed fragmentation pathways of impurity-A

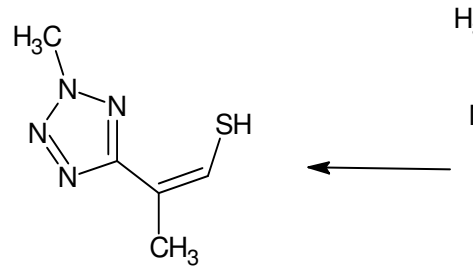

$\mathrm{m} / \mathrm{z} 156$

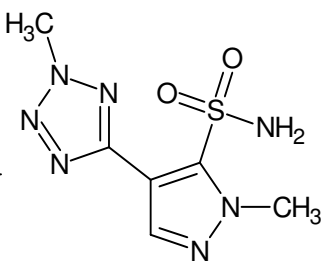

$\mathrm{m} / \mathrm{z} 244.3$

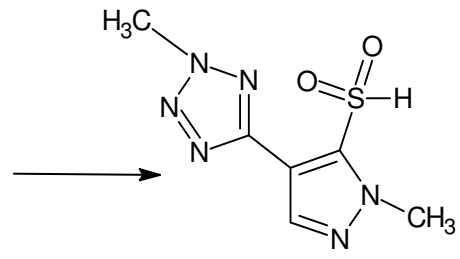

$\mathrm{m} / \mathrm{z} 226.9$

Figure 8. Proposed fragmentation pathways of impurity-B 


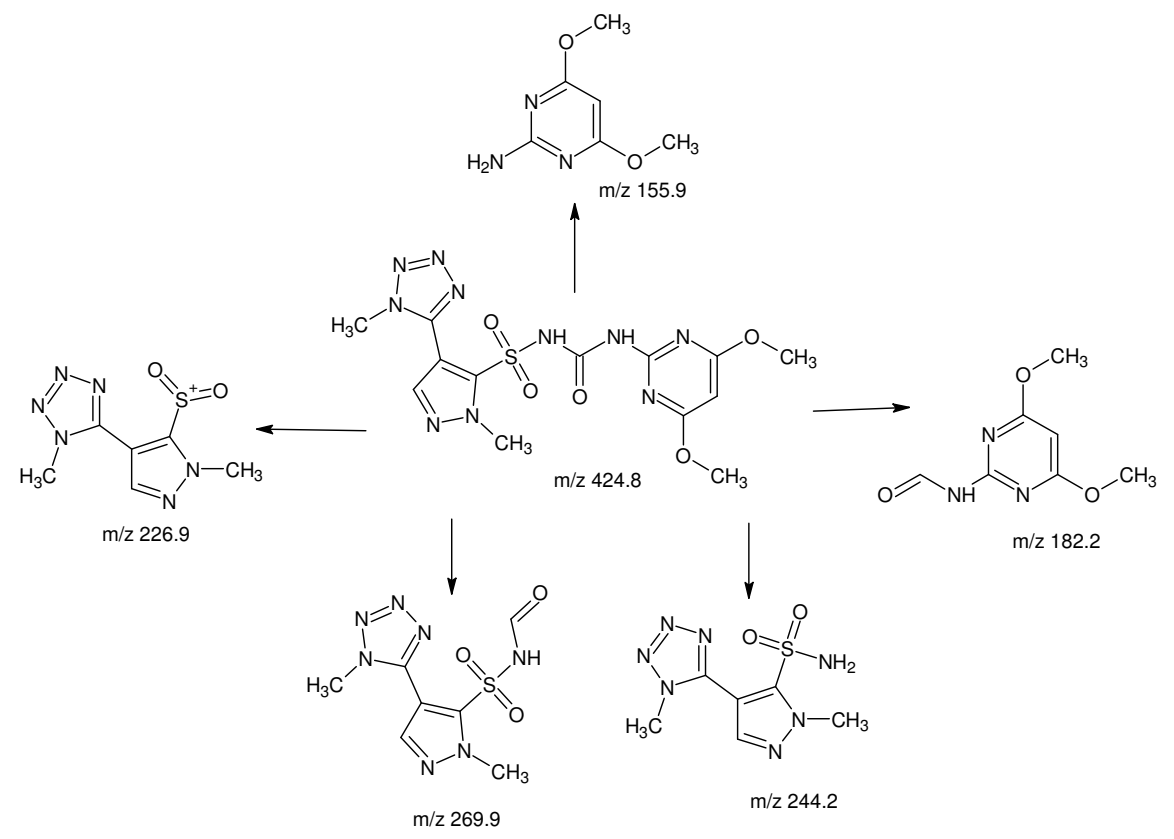

Figure 9. Proposed fragmentation pathways of impurity-D

\section{Structural elucidation of impurity A}

The LC-MS/MS, IR and NMR data of the impurity-A were compared with those of azimsulfuron. The major fragments obtained by MS/MS analysis, functional groups from FTIR, ${ }^{1} \mathrm{H}$ NMR and ${ }^{13} \mathrm{C}$ NMR spectral data are given in Table 1, 2 and 3, respectively. The MS/MS analysis data of the compound exhibited the molecular ion peak $(\mathrm{M}+1)$ at 155.9 amu and fragmentation pattern also confirmed the structure (Figure 7). The IR absorption at $3412.86,3026.14,1637.52,1583.14$ and $1216.97 \mathrm{~cm}^{-1}$ revealed the compound contained $\mathrm{NH}, \mathrm{CH}, \mathrm{C}=\mathrm{C}, \mathrm{C}=\mathrm{N}$ and $\mathrm{C}-\mathrm{O}$ groups, respectively. In the proton $\mathrm{NMR}$ spectrum of impurity-A, a singlet appeared at $\delta 3.75 \mathrm{ppm}$ accounted for six protons, which is corresponding to the two methoxy groups $\left(-\mathrm{OCH}_{3}\right)$ having the same chemical environment (Table 3). Signal at $\delta 6.57 \mathrm{ppm}$ as broad singlet revealed that the compound containing amine group, which is disappeared on $\mathrm{D}_{2} \mathrm{O}$ exchange analysis. Similarly the ${ }^{13} \mathrm{C}$ NMR spectrum of impurity-A having signals at $\delta 53.5$ and $\delta 172.0 \mathrm{ppm}$ corresponding to methoxy and methoxy attached quaternary carbon in pyrimidine ring, respectively. On the basis of the spectral data it was inferred that the tetrazole and pyrazole ring of azimsulfuron was not present in the impurity-A. Based on the above LC-MS/MS, IR and NMR spectral data, it was concluded that the impurity-A was 2-amino-4,6-dimethoxy pyrimidine.

\section{Structural elucidation of impurity $B$}

The IR spectrum at 3206.91, 3129.13, 1600.13, 1560.13, 1356.97, 1175.93 and $1263.95 \mathrm{~cm}^{-1}$ showed the presence of $\mathrm{NH}, \mathrm{CH}, \mathrm{C}=\mathrm{C}, \mathrm{C}=\mathrm{N}, \mathrm{O}=\mathrm{S}=\mathrm{O}$ and $\mathrm{C}-\mathrm{N}$ groups, respectively. The ${ }^{1} \mathrm{H}$ NMR spectrum of impurity B reveals that the two methyl groups at $\delta 4.13$ and $4.42 \mathrm{ppm}$ were present in the two different chemical environments, one methyl attached to tetrazole and other methyl attached to pyrazole ring. Signals at $\delta 7.94 \mathrm{ppm}$ and $\delta 7.95 \mathrm{ppm}$ corresponding to pyrazole and amine protons, respectively. Similarly in ${ }^{13} \mathrm{C}$ NMR spectrum, the signal at $\delta 157.2 \mathrm{ppm}$ corresponding to tetrazole carbon. The signals at $\delta 39.5$ and 39.7 
ppm reveals that the two methyl carbons in two different chemical environment position (Table 3). The LC-MS/MS analysis of this impurity B shows the molecular ion $(\mathrm{M}+1)$ at $244.3 \mathrm{amu}$, which indicates actual molecular weight is 243 . The odd number of molecular weight indicates the odd number of nitrogen atoms present in the structure. Major fragments were at $\mathrm{m} / \mathrm{z}, 226.9$ and $156.1 \mathrm{amu}$. The $\mathrm{m} / \mathrm{z} 226.9 \mathrm{amu}$ corresponds to 5-[5-(dioxidesulfanyl)-1-methyl-pyrazol-4-yl]-2-methyl-tetrazole, which is breakage of amine group from the molecular ion peak. The other one $\mathrm{m} / \mathrm{z} 156.1$ is corresponding to 2-(2-methyl-tetrazole-5yl) prop-1-ene-1-thiol (Figure 8). Based on the above data, impurity B was characterized as "1-methyl-4-(2-methyl-2H-tetrazol-5-yl)-1H-pyrazole-5-sulfonamide".

\section{Structural elucidation of impurity $C$}

The IR, LC-MS/MS, ${ }^{1} \mathrm{H}$ NMR and ${ }^{13} \mathrm{C}$ NMR spectral analysis of the impurity $\mathrm{C}$ are given in Tables 1, 2 and 3. The LC-MS/MS analysis data of the impurity exhibited the molecular ion peak (M-1) at 93.1 amu and major fragment $m / z 65.2$ also confirms the structure. From ${ }^{1} \mathrm{H}$ NMR and ${ }^{13} \mathrm{C}$ NMR signals corresponding to aromatic protons and carbons were studied and tabulated in Table 3. Quite interestingly, standard purchased from sigma-Aldrich and impurity $\mathrm{C}$ was comparable in the HPLC chromatogram. Based on the above data the structure of the impurity $\mathrm{C}$ was characterized as phenol.

\section{Structural elucidation of impurity $D$}

The MS, IR and ${ }^{1} \mathrm{H}$ NMR data of the impurity-D were compared with those of azimsulfuron. The major fragments obtained by MS/MS analysis are given in Table 1. Five major fragment ions were detected in the impurity $\mathrm{D}, \mathrm{m} / \mathrm{z}, 269.9,244.2,226.9,182.2$ and $155.9 \mathrm{amu}$. The first fragment $\mathrm{m} / z, 269.9$ is corresponding to loss of 2-amino-4, 6-dimethoxy pyrimidine. Second fragment $m / z 244.2$ is corresponding to 1-methyl-4-(1-methyl-tetrazol-5-yl)-pyrazol5 -sulfonamide. Third fragment $\mathrm{m} / \mathrm{z} 226.9$ is corresponding to loss of amine group from fragment $\mathrm{m} / \mathrm{z}$ 244.2. The fourth major fragment $\mathrm{m} / \mathrm{z} 182.2$ is corresponding to (4, 6dimethoxypyrimidine-2-yl) formamide and the last fragment $\mathrm{m} / \mathrm{z} 155.9$ is 2-amino-4, 6dimethoxy pyrimidine (Figure 9). All the above fragments $m / z$ values were matching with azimsulfuron fragment pattern and its $m / z$ values.

The ${ }^{1} \mathrm{H}$ NMR spectrum of impurity D exhibited two separate peaks at $\delta 4.02$ and $4.27 \mathrm{ppm}$ for the two methyl group protons on the tetrazole and pyrazole ring which indicated that these two methyl group protons are chemically non-equivalent. It was quite interesting to note that the difference of $\delta \mathrm{ppm}$ between the two methyl groups in impurity D was $0.25 \mathrm{ppm}$ and azimsulfuron spectrum shows the difference is $0.04 \mathrm{ppm}$. This difference in $\delta$ value reveals that the methyl group is attached to the different position in the tetrazole ring of impurity D. This is further confirmed by comparing NOE (Nuclear Overhauser Effect) of it with azimsulfuron. It was found that NOE interaction between methyl protons of tetrazole ring with pyrazole ring proton of impurity D. There is no NOE interaction between methyl protons of tetrazole ring in azimsulfuron with pyrazole proton. Based on NOE results, concluded that methyl group on tetrazole ring is at 2-position in impurity D (Figure 12). ${ }^{1} \mathrm{H}$ NMR spectrum of this impurity D exhibited signal integrating for six protons for two methoxy groups at $\delta 3.88$ ppm on the pyrimidine ring indicating they are in chemically equivalent environment. The proton NMR reveals the pyrazole proton exhibited at $\delta 6.05 \mathrm{ppm}$ and carbamide two $\mathrm{NH}$ protons are at $\delta 10.82$ and $13.1 \mathrm{ppm}$ (Table 3 ). Similarly, the ${ }^{13} \mathrm{C}$ NMR spectrum also reveals that the impurity D were comparable with that of azimsulfuron. The peaks in the IR spectrum at $3086.31,2951.70,1741.55,1612.13,1579.88,1363.02,1197.42$ and 1208.95 reveals that the compound contains $\mathrm{NH}, \mathrm{CH}, \mathrm{C}=\mathrm{O}, \mathrm{C}=\mathrm{N}, \mathrm{O}=\mathrm{S}=\mathrm{O}$ and $\mathrm{C}-\mathrm{O}$ groups, respectively. 
Based on these spectral results, it was confirmed that the impurity having the molecular formula $\mathrm{C}_{13} \mathrm{H}_{16} \mathrm{~N}_{10} \mathrm{O}_{5} \mathrm{~S}$ and the same was characterized as $N$-[(4,6-dimethoxypyrimidin-2yl)carbamoyl]-1-methyl-4-(1-methyl-1H-tetrazol-5-yl)- $1 H$-pyrazole-5-sulfonamide.

Table 2. IR spectral data of azimsulfuron and its impurities

\begin{tabular}{cccccccc}
\hline $\begin{array}{c}\text { Azimsulfuron } \\
\mathrm{cm}^{-1}\end{array}$ & $\begin{array}{c}\text { Imp-A, } \\
\mathrm{cm}^{-1}\end{array}$ & $\begin{array}{c}\text { Imp-B, } \\
\mathrm{cm}^{-1}\end{array}$ & $\begin{array}{c}\text { Imp-C, } \\
\mathrm{cm}^{-1}\end{array}$ & $\begin{array}{c}\text { Imp-D, } \\
\mathrm{cm}^{-1}\end{array}$ & $\begin{array}{c}\text { Imp-E, } \\
\mathrm{cm}^{-1}\end{array}$ & $\begin{array}{c}\text { Imp-F, } \\
\mathrm{cm}^{-1}\end{array}$ & $\begin{array}{c}\text { Group } \\
\text { assignment }\end{array}$ \\
\hline 3173.53 & 3412.86 & 3206.91 & 3346.15 & 3086.31 & 3362.93 & 3367.04 & $\begin{array}{c}\text { NH Stretching\& } \\
\text { OH Stretching }\end{array}$ \\
3019.89 & 3026.14 & 3129.13 & 3087.91 & 2951.70 & 2954.79 & 2956.72 & C-H Stretching \\
1700.08 & - & - & - & 1741.55 & 1728.73 & 1787.75 & C=O Stretching \\
1606.07 & 1637.52 & 1600.13 & 1593.98 & 1612.13 & 1615.48 & 1594.63 & C=C Stretching \\
1575.44 & 1583.14 & 1560.13 & - & 1579.88 & 1579.88 & 1536.37 & C=N Stretching \\
$1362.87 \&$ & - & $1356.97 \&$ & - & $1363.02 \&$ & - & - & O=S=O \\
1168.02 & & 1175.93 & & 1197.42 & & & $\begin{array}{c}\text { Stretching } \\
122.29\end{array}$ \\
1216.97 & 1263.95 & 1229.11 & 1208.95 & 1224.03 & 1208.63 & C-O Stretching \& \\
& & & & & & & C-N Stretching \\
\hline
\end{tabular}

Table 3. ${ }^{1} \mathrm{H}$ NMR and ${ }^{13} \mathrm{C}$ NMR assignments for azimsulfuron and impurities

\begin{tabular}{|c|c|c|c|c|c|c|c|c|}
\hline \multirow[t]{2}{*}{ Position } & \multicolumn{2}{|c|}{ Azimsulfuron } & \multicolumn{2}{|c|}{ Impurity A } & \multicolumn{2}{|c|}{ Impurity B } & \multicolumn{2}{|c|}{ Impurity $\mathrm{C}$} \\
\hline & $\overline{\mathrm{M} /{ }^{1} \mathrm{H} / \mathrm{ppm}}$ & ${ }^{13} \mathrm{C}$ & $\mathrm{M} /{ }^{1} \mathrm{H} / \mathrm{ppm}$ & ${ }^{13} \mathrm{C}$ & $\mathrm{M} /{ }^{1} \mathrm{H} / \mathrm{ppm}$ & ${ }^{13} \mathrm{C}$ & $\mathrm{M} /{ }^{1} \mathrm{H} / \mathrm{ppm}$ & ${ }^{13} \mathrm{C}$ \\
\hline 1,2 & $\mathrm{~s} / 6 \mathrm{H} / 3.96$ & 54.70 & $\mathrm{~s} / 6 \mathrm{H} / 3.75$ & 53.56 & $\begin{array}{l}\mathrm{s} / 3 \mathrm{H} / 4.13 \\
\mathrm{~s} / 3 \mathrm{H} / 4 \mathrm{4}\end{array}$ & $\begin{array}{l}39.59 \\
3971\end{array}$ & $\mathrm{~m} / 2 \mathrm{H} / 7.15$ & 129.78 \\
\hline 3 & $\mathrm{~s} / 3 \mathrm{H} / 4.31$ & 40.87 & $\mathrm{~s} / 1 \mathrm{H} / 5.34$ & 78.29 & $\mathrm{~s} / 1 \mathrm{H} / 7.94$ & 138.17 & $\mathrm{~m} / 1 \mathrm{H} / 6.92$ & 119.20 \\
\hline 4 & $\mathrm{~s} / 3 \mathrm{H} / 4.27$ & 39.53 & brs / $2 \mathrm{H} / 6.57$ & - & $\mathrm{brs} / 1 \mathrm{H} / 7.95$ & - & & 115.64 \\
\hline 5 & $\mathrm{~s} / 1 \mathrm{H} / 6.06$ & 84.07 & & 163.20 & & 109.50 & $\mathrm{~m} / 2 \mathrm{H} / 6.85$ & 115.64 \\
\hline 6 & $\mathrm{~s} / 1 \mathrm{H} / 8.13$ & 138.18 & & 172.04 & & 140.69 & - & 157.73 \\
\hline 7 & $\mathrm{brs} / 1 \mathrm{H} / 13.21$ & & & 172.04 & & 157.27 & $\mathrm{~s} / 1 \mathrm{H} / 5.45$ & \\
\hline 8 & $\mathrm{brs} / 1 \mathrm{H} / 10.86$ & & & & & & & \\
\hline 9 & & 111.24 & & & & & & \\
\hline 10 & & 135.28 & & & & & & \\
\hline 11 & & 156.79 & & & & & & \\
\hline 12,15 & & 171.14 & & & & & & \\
\hline 13 & & 155.65 & & & & & & \\
\hline 14 & & 149.39 & & & & & & \\
\hline & Azimsulf & iron & Impurity & & Impurity & & Impurity & \\
\hline : & $\begin{array}{c}\mathrm{M} /{ }^{1} \mathrm{H} / \\
\mathrm{ppm}\end{array}$ & ${ }^{13} \mathrm{C}$ & $\mathrm{M} /{ }^{1} \mathrm{H} / \mathrm{ppm}$ & ${ }^{13} \mathrm{C}$ & $\mathrm{M} /{ }^{1} \mathrm{H} / \mathrm{ppm}$ & ${ }^{13} \mathrm{C}$ & $\mathrm{M} /{ }^{1} \mathrm{H} / \mathrm{ppm}$ & ${ }^{13} \mathrm{C}$ \\
\hline 1,2 & $\mathrm{~s} / 6 \mathrm{H} / 3.96$ & 54.70 & $\mathrm{~s} / 6 \mathrm{H} / 3.88$ & 55.02 & $\mathrm{~s} / 12 \mathrm{H} / 3.91$ & 54.58 & $\mathrm{~s} / 6 \mathrm{H} / 3.86$ & 53.96 \\
\hline 3 & $\mathrm{~s} / 3 \mathrm{H} / 4.31$ & 40.87 & $\mathrm{~s} / 3 \mathrm{H} / 4.27$ & 40.41 & $\mathrm{~s} / 2 \mathrm{H} / 5.91$ & 84.07 & $\mathrm{~s} / 1 \mathrm{H} / 5.93$ & 84.02 \\
\hline 4 & $\mathrm{~s} / 3 \mathrm{H} / 4.27$ & 39.53 & $\mathrm{~s} / 3 \mathrm{H} / 4.02$ & 34.62 & $\mathrm{brs} / 2 \mathrm{H} / 11.10$ & & $\mathrm{~m} / 2 \mathrm{H} / 7.40-$ & 12040 \\
\hline 5 & $\mathrm{~s} / 1 \mathrm{H} / 6.06$ & 84.07 & $\mathrm{~s} / 1 \mathrm{H} / 6.04$ & 84.55 & & 156.83 & 7.45 & 129.40 \\
\hline 6 & $\mathrm{~s} / 1 \mathrm{H} / 8.13$ & 138.18 & $\mathrm{~s} / 1 \mathrm{H} / 8.15$ & 138.11 & & 171.74 & $\begin{array}{c}\mathrm{m} / 1 \mathrm{H} / 7.25- \\
7.28\end{array}$ & 125.56 \\
\hline 7 & $\mathrm{brs} / 1 \mathrm{H} / 13.21$ & & brs/ $1 \mathrm{H} / 13.25$ & & & 149.07 & $\mathrm{~m} / 2 \mathrm{H} / 7.40-$ & 12108 \\
\hline 8 & $\mathrm{brs} / 1 \mathrm{H} / 10.86$ & & brs/ 1H /10.86 & & & & 7.45 & 121.98 \\
\hline 9 & & 111.24 & & 110.80 & & & $\mathrm{~s} / 1 \mathrm{H} / 10.80$ & \\
\hline 10 & & 135.28 & & 134.82 & & & & 17160 \\
\hline 11 & & 156.79 & & 156.30 & & & & $1 / 1.00$ \\
\hline 12,15 & & 171.14 & & 171.05 & & & & 156.47 \\
\hline 13 & & 155.65 & & 154.95 & & & & 150.03 \\
\hline 14 & & 149.39 & & 149.10 & & & & 150.32 \\
\hline
\end{tabular}




\section{Structural elucidation of impurity $E$}

The mass spectrum of impurity E exhibited a molecular ion peak $(\mathrm{M}+1)$ at $337.1 \mathrm{amu}$, which shows that the actual molecular weight is equal to $336 \mathrm{amu}$. The even molecular weight of impurity $\mathrm{E}$ indicates the possible presence of even number of nitrogen atoms in the molecule. The MS/MS data shows the major fragments at $\mathrm{m} / \mathrm{z} 181.9,155.9$ and $139.0 \mathrm{amu}$ (Table 1). The $\mathrm{m} / \mathrm{z} 181.9 \mathrm{amu}$ fragment corresponding to loss of 2-amino-4, 6-dimethoxy pyrimidine which is the major fragment $\mathrm{m} / \mathrm{z} 155.9$ amu of molecular ion peak (Figure 10). In IR spectrum, the absorption bands at 3362.93, 2954.79, 1728.73, 1615.48, 1579.88 and $1224.03 \mathrm{~cm}^{-1}$ revealed that the compound contain $\mathrm{NH}, \mathrm{CH}, \mathrm{C}=\mathrm{O}, \mathrm{C}=\mathrm{C}, \mathrm{C}=\mathrm{N}$ and $\mathrm{C}-\mathrm{O}$ groups, respectively (Table 1).<smiles>COc1cc(OC)nc(NC(=O)Nc2nc(OC)cc(OC)n2)n1</smiles><smiles>COc1cc(OC)nc(NC=O)n1</smiles>

Figure 10. Proposed fragmentation pathways of impurity-E

${ }^{1} \mathrm{H}$ NMR spectrum of this impurity E exhibited signal at $\delta 3.91 \mathrm{ppm}$ integrating for twelve protons of four methoxy groups on the pyrimidine ring, indicating they are in chemically equivalent environment. The carbamide proton exhibited as broad singlet at $\delta$ $11.10 \mathrm{ppm}$ and the pyrimidine protons integrated as two protons at $\delta 5.91 \mathrm{ppm}$ as singlet also confirms that they are chemically equivalent. Similarly, the ${ }^{13} \mathrm{C}$ NMR spectrum reveals the carbonyl group appearing at $\delta 149.0 \mathrm{ppm}$ and the methoxy group attached to pyrimidine carbons appearing at $\delta 171.7 \mathrm{ppm}$. Based on these spectral data, it was confirmed that the impurity having the molecular formula $\mathrm{C}_{13} \mathrm{H}_{16} \mathrm{~N}_{6} \mathrm{O}_{5}$ and the same was characterized as 1, 3-bis(4, 6-dimethoxypyrimidin-2-yl)urea.

\section{Structural elucidation of impurity $F$}

${ }^{1} \mathrm{H}$ NMR spectrum of this impurity E exhibited signal integrating for six protons for two methoxy groups at $\delta 3.86 \mathrm{ppm}$ on the pyrimidine ring indicating that they are in chemically equivalent environment. The amide proton exhibited as singlet at $\delta 10.80 \mathrm{ppm}$ and also the pyrimidine proton appeared at $\delta 5.93 \mathrm{ppm}$ as singlet. Similarly the ${ }^{13} \mathrm{C}$ NMR spectrum reveals that the carbonyl group appeared at $\delta 150.3 \mathrm{ppm}$ and methoxy groups attached pyrimidine carbon appeared at $\delta 171.6 \mathrm{ppm}$ (Table 3 ). The IR spectrum at 3367.04, 2956.72, $1787.75,1594.63,1536.37$ and $1208.63 \mathrm{~cm}^{-1}$ corresponding to $\mathrm{NH}, \mathrm{CH}, \mathrm{C}=\mathrm{O}, \mathrm{C}=\mathrm{C}, \mathrm{C}=\mathrm{N}$ and $\mathrm{C}-\mathrm{O}$ groups, respectively. The MS/MS analysis reveals the molecular ion peak $(\mathrm{M}+1)$ at $276.0 \mathrm{amu}$ and major fragments were detected at $\mathrm{m} / \mathrm{z}, 182.1,157$ and $139.1 \mathrm{amu}$ (Table 1). 
The major fragment $\mathrm{m} / \mathrm{z} 182.1 \mathrm{amu}$ is corresponding to (4, 6-dimethoxypyrimidin-2-yl) formamide and $\mathrm{m} / \mathrm{z} 139 \mathrm{amu}$ is 4, 6-dimethoxypyrimidine (Figure 11). Based on the spectral data, the structure of impurity $\mathrm{F}$ was characterized and concluded as phenyl (4, 6dimethoxypyrimidin-2-yl) carbamate.<smiles>COc1cc(OC)nc(NC=O)n1</smiles>

Figure 11. Proposed fragmentation pathways of impurity-F

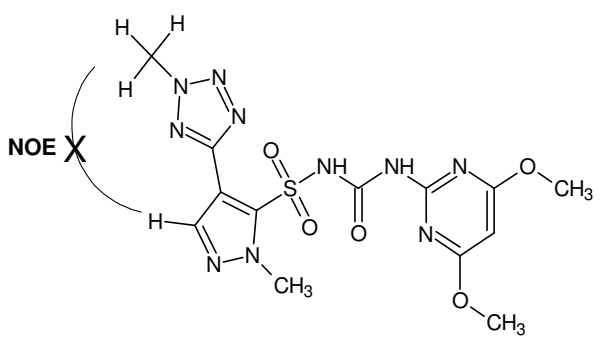

Azimsulfuron<smiles></smiles>

Impurity D

Figure 12. NOE interaction of azimsulfuron and impurity-D

\section{Conclusion}

Azimsulfuron is an important selective potent herbicide for weed control in rice-paddies, wheat, barley, etc. The present research work describes a HPLC method for detection, separation of six process related impurities from azimsulfuron technical and preparative HPLC method for isolation of two impurities from the azimsulfuron technical. All the six impurities detected were characterized using IR, LC-MS/MS and NMR experimental data.

\section{Acknowledgment}

The authors wish to thank Rallis India Ltd, Bangalore for giving the research sample of azimsulfuron technical material to carry out the research work. Authors also thank the Department of Chemistry, Mangalore University, India.

\section{References}

1. Polati S, Bottaro M, Frascarolo P, Gosetti F, Gianotti V and Gennaro M C, Anal Chemica Acta, 2006, 579(2), 146-151; DOI:10.1016/j.aca.2006.07.034

2. Beyer E M, Duffy M J, Hay J V, Schlueter D D, Kearney P C and Kaufman D D, Chemistry, Degradation and Mode of Action, (Eds.), Herbicides. 1988, 3, 117-189.

3. Brown H M, Pestic Sci., 1990, 29(3), 263-281.

4. Hay J V, Pestic Sci., 1990, 29(3), 247-261.

5. Susumu Y, Toshiaki S, Yoshihiro I, Fumio S, Takashi I, Koichi S and Tsutomu N, J Pesticide Sci., 1990, 15(4), 531-538; DOI:10.1584/jpestics.15.531

6. Shirakura S, Ito K, Gee S K, Barefoot A C and Aizawa H, Weed Res., 1995, 40, 299-307.

7. Palimkar S S, Pawar J D, Sankar B, Prosenjit B, Subhash R K, Rama Mohan H, Venkatesh P M, Hari N P, Vadiraj G S and Avinash S M, Process of preparation of Azimsulfuron, Patent No. WO2014002111A1, 2014. 
8. Palimkar S S, Pawar J D, Sankar B, Prosenjit B, Subhash R K, Rama Mohan H, Venkatesh P M, Hari N P, Vadiraj G S, Avinash S M, Substituted tetrazole compounds and process thereof, Patent No. WO2014002109A1, 2014.

9. S. S. Palimkar, J. D. Pawar, B. Sankar, B. Prosenjit, R. K. Subhash, H. Rama Mohan, P. M.Venkatesh, N. P. Hari, G. S. Vadiraj, S. M. Avinash, Substituted pyrazole compounds and process for preparation thereof, Patent No. WO2014002110A1, 2014.

10. Barefoot A C, Armbrust K, Fader T, Kato Y and Sato K, Pesticide Chem., 1996, 97-104.

11. Khan M N, Bakar B B and Yin F W N, Int J Chem Kinet., 1999, 31(4), 253-260; DOI:10.1002/(SICI)1097-4601(1999)31:4<253::AID-KIN2>3.0.CO;2-X

12. Pusino A, Pinna M V and Gessa C, J Agric Food Chem., 2004, 52(11), 3462-3466; DOI:10.1021/jf049971e

13. Pinna M V, Pusino A and Gessa C, J Agric Food Chem., 2004, 52(26), 8081-8085; DOI;10.1021/jf048722n

14. Valle A, Boschin G, Negri M, Abbruscato P, Sorlini C,'Agostina A D and Zanardini E, J Appl Microbiol., 2006, 101(2), 443-452; DOI:10.1111/j.1365-2672.2006.02937.x 